\title{
FEUERBACH E ESPINOSA: DEUS E NATUREZA, DUALISMO OU UNIDADE? ${ }^{1}$
}

Eduardo Ferreira CHAGAS ${ }^{2}$

- RESUMO: O presente artigo evidencia, por um lado, o mérito da filosofia de Espinosa, pelo fato de haver submetido a oposição das partes e do todo, do corpo e da alma, da matéria e do espírito, à unidade da substância, já que toda parte singular da substância pertence à sua natureza. Por outro lado, destaca a crítica de Feuerbach a Espinosa, porque a filosofia deste é, na verdade, uma filosofia da identidade, que não reconhece, como Hegel também assinala, a substância como espírito e o espírito como substância, e não determina suficientemente a unidade da matéria e do espírito, já que falta a ela a realidade da diferença, da determinidade. Enquanto Espinosa identifica Deus com a natureza (Deus sive natura) e, mediante a natureza divina (a substância), supera a contradição de Descartes entre matéria (res extensa) e espírito (res cogitans), Feuerbach quer, em oposição ao panteísmo, a diferença entre natureza e Deus (aut Deus aut natura).

- PALAVRAS-CHAVE: Deus e Natureza em Espinosa; Crítica a Espinosa; Feuerbach.

O tema da unidade do espírito e da matéria (natureza) é latente na filosofia moderna, é mister ressaltar que

Descartes e seus discípulos Geulincx e Malebranche têm primeiro por objeto a diferença entre natureza e espírito, entre extensão e pensamento, e desenvolvem natureza e espírito como totalidade, os quais foram, no entanto, definidos para si, independentes um do outro. (Cornehl, 1969, p.82)

1 Resultado de pesquisa apoiada pelo CNPq

2 Professor Doutor do Departamento de Filosofia e do Programa de Pós-Graduação em Filosofia da Universidade Federal do Ceará-UFC. Artigo recebido em jul/06 e aprovado para publicação em nov/06 
Esses filósofos partem do dualismo entre espírito e matéria e insistem naquela posição, segundo a qual a essência da matéria consiste apenas na extensão (Ausdehnung) e a do espírito no pensamento (Denken), por assim dizer como dois modos particulares da essência ou duas essências opostas. Disso se segue que se põe aqui como problema filosófico central a pergunta pela reconciliação ou unidade do espírito e da matéria. Em Descartes e Malebranche, esta unidade era "arbitrária", "artificial", e não real, porque ela estava fundada na essência de Deus. Deus (Gott) atua em ambos os filósofos como um terceiro, para mediar a unidade de pensamento (cogitatio) e matéria (extensio). Em princípio, Espinosa, ao contrário, suprime, em seu conceito de substância, esta oposição entre espírito e matéria, pois, para ele, ambas as substâncias não são autônomas, mas tão-somente atributos de uma e mesma substância. É precisamente este conceito de substância, na forma de uma unidade, que conduz Feuerbach ao panteísmo. Em princípio, Feuerbach aceita o panteísmo como uma tentativa para superar a contradição do espírito em relação à natureza, entre a realidade espiritual e a sensível, o pensamento e o produto do pensamento, isto é, no intermédio da idéia (o original) com a natureza (o deduzido).

Resumiremos, en passant, tanto a filosofia de Malebranche quanto a de Descartes para evidenciar a passagem de ambas para Espinosa. A filosofia de Malebranche contém os elementos da filosofia de Espinosa, muito mais determinado e desenvolvido do que a do cartesianismo. Se esses elementos, ainda dispersos em Malebranche, fossem pensados e concebidos como um todo, "assim teríamos", como diz Feuerbach, "o Espinosa" (Feuerbach, 1969, p.362). Já em Malebranche, Deus é como uma essência única e autônoma, como razão universal, o espírito dos espíritos, o lugar ou a unidade universal de todos os espíritos. Isto é, todos os espíritos, não obstante sua existência externa e autonomia, têm em Deus seu conteúdo e sua essência. Por natureza (ou matéria) Malebranche nomeia os elementos, com os quais o espírito se liga. Esta ligação de espírito e natureza é, todavia, meramente um efeito, conseqüência do poder de Deus ou de sua vontade. Se, porém, tal ligação foi representada como dependente do querer divino, já que Deus serve de base a ela, não há nenhuma relação necessária e interna entre o espírito e a matéria. A matéria não pode pensar e o espírito não pode ser extenso, mas ambos estão numa relação necessária com Deus, porque eles participam dEle. Disso resulta que a matéria enquanto tal foi em Malebranche reduzida, por assim dizer, a "uma pura forma", que não tem nenhuma consistência, nenhuma existência para si; pelo contrário, ela é pura e simplesmente uma Modifikation da essência de Deus, já que a realidade ou a verdadeira essência (a substância) é, no fundo, apenas Deus. Apesar disso, serve de base ao pensamento de Malebranche a noção de que Deus (a essência universal) é o substancial do espírito e da matéria. Por conseguinte, já nesta sua consideração sobre Deus, concebido como o substancial, como 
a identidade de espírito e matéria (isto é, Deus entendido como realidade espiritual e, simultaneamente, material), pode-se reconhecer o núcleo da substância espinosana.

Descartes designa, outrossim, a substância (Substanz) como uma essência que não necessita de nenhum auxílio, de nenhum outro ser, para existir. A esta substância perfeita, causa de si mesma (causa sui), nomeia ele Deus. Fora da substância divina, no entanto, ele concebe ainda duas outras substâncias: a corporal ou extensa (res extensa) e a pensante ou espiritual (res cogitans). Ambas podem ser concebidas sob uma determinação comum, qual seja, que elas precisam da colaboração e do auxílio de Deus (concursus Dei) para a sua existência. Em Descartes existem, então, três substâncias e, na verdade, duas finitas, criadas, a corporal (extensa) e a pensante, e uma substância infinita, incriada e independente, isto é, Deus. Devemos acentuar que as substâncias criadas (matéria e pensamento) são, no que tange seu conceito, autônomas e independentes e, na verdade, não apenas uma da outra, como também de Deus, pois uma não pode ser deduzida da outra. Assim pertence, por exemplo, ao conceito da matéria nada mais do que a extensão, que constitui a sua essência, a sua qualidade essencial. Pela extensão, não por Deus, nem pelo pensar, é a matéria o que ela é, a saber, essencialmente uma coisa extensa, por conseguinte ela se refere não ao conceito de Deus, mas meramente a si mesma. A matéria "expressa em Descartes nada, ela representa nada mais do que a si mesma" (idem, p.365). Isso não significa que ela esteja fora de Deus. Trata-se aqui apenas disso, a saber, demonstrar a determinação da matéria no que tange seu conceito, isto é, que ela não depende de Deus, mas apenas da própria extensão. A extensão é a essência, a subsistência da matéria, pois se pode muito bem tirar as qualidades sensíveis da matéria, sem que se perca, com isto, o conceito dela, mas não se pode retirar a extensão, sem que a matéria não se torne nada. Para ilustrar isso, menciona Descartes uma figura que não pode ser pensada sem a extensão, porque no conceito da figura a extensão está contida como seu fundamento, como sua determinação positiva, já que ela se refere essencialmente, segundo o seu conceito, à extensão. O triângulo, que é limitado pelos seus três lados, tem, por exemplo, para seu fundamento a extensão; ele é uma determinação (Modifikation) finita, limitada, da extensão, com isto ele, como uma maneira da extensão, não pode ser sem esta. Correspondendo a isso, vale também para o pensamento, em cujo conceito encontra-se nada mais do que a reflexion sobre si mesma, aquilo pelo qual ele é o que ele é, isto é, uma coisa pensante sem extensão em comprimento, largura e profundidade. Com outras palavras: em Descartes, ambas as substâncias, a saber, a extensão (extensio) e o pensamento (cogitatio), são, pois, segundo o seu conceito, independentes (unabhängig) e autônomas (selbständig), embora elas, segundo sua existência deduzida, sejam dependentes (abhängig) e não autônomas (unselbständig), porque 
elas, como mencionado, não podem, de maneira nenhuma, consistir sem Deus (sem a substância infinita). Disso conclui Feuerbach que Descartes, "o teólogo", e Descartes, "o filósofo", "estão, um com o outro, em luta", pois matéria e pensamento "foram concebidos independentes, mas apresentados dependentes" (idem, p.376). O conceito de substância tem em Descartes sua existência e realidade em Deus, no qual a matéria e o pensamento concordam como essências criadas e dependentes. Desta perspectiva, segundo a qual a matéria e o pensamento têm em comum o conceito de substância, apesar da autonomia e da independência de uma para a outra, vê-se a passagem de Descartes para Espinosa.

Os princípios gerais e fundamentais da filosofia espinosana podem ser expressos da seguinte maneira: definições (I) - 1 por causa de si mesma (causa sui), entende Espinosa aquilo cuja essência inclui em si a existência, ou seja, aquilo cuja essência só pode ser pensada como existente; isto é, a causa de si mesma (Ursache seiner selbst) existe fundamentada em si mesma e é, por conseguinte, necessária; 2 como coisa finita (res finita), designa ele aquilo que pode ser limitado por outra coisa de igual natureza, como, por exemplo, corpos por corpos e pensamentos por pensamentos, em que, é claro, nem os corpos podem ser limitados por pensamentos nem os pensamentos por corpos; 3 por substância (substantia), entende ele aquilo que é em si e pensado ou concebido por si, isto é, algo cujo conceito não precisa do conceito de outra coisa, por exemplo, do corpo ou do espírito, para ser formado; quer dizer, a substância existe sozinha, autonomamente; 4 atributo (attributa) é aquilo que o entendimento (intellectus) reconhece como a essência da substância, por exemplo, a extensão (extensio) como a essência da matéria e o pensamento (cogitatio) como a essência do espírito; o atributo não existe independente, autônomo, pois ele pertence, de maneira necessária, à substância; 5 como modo (modus), ou seja, maneira, particularidade ou determinidade, concebe ele as afecções (Affektionen), as variações (Modifikationen), da substância, ou aquilo que está em outro, ou formado ou pensado por outro, isto é, as condições finitas da substância, como, por exemplo, o mundo, o homem, a idéia, a vontade, o amor etc; o modo designa apenas a condição da substância e, com isto, não pertence, necessariamente, a ela; 6 por Deus, entende ele o ser absolutamente infinito (summum ens), isto é, a substância que consiste de infinitos atributos; ou seja, Deus contém em si tudo; 7 como livre (libera), nomeia ele uma coisa (res) que existe exclusivamente da necessidade de sua própria natureza, e necessário (necessaria) chama ele uma coisa que é determinada por outro, para existir e operar de uma maneira determinada; e 8 por eternidade, entende ele a existência concebida como uma consequência necessária da Definition das coisas eternas. 
Em relação aos Axiomas (II) de Espinosa, podemos resumi-los assim: 1-tudo, o que consiste, é ou existe em si ou num outro; 2- mas o que não pode ser pensado por um outro deve ser, por conseguinte, concebido por si mesmo; 3- de uma causa determinada resulta necessariamente um efeito determinado, e, vice-versa, o efeito indica a sua causa; 4- mas o conhecimento do efeito é, por sua vez, dependente do conhecimento da causa e a inclui; 5- as coisas que nada tenham de comum entre si não podem, de maneira nenhuma, ser concebidas umas pelas outras, porque o conceito de uma não inclui o conceito da outra; 6- a idéia verdadeira concorda, a rigor, com seu objeto e 7- algo, cuja essência não envolve a existência, não pode ser pensado como existente.

Por fim, erguem-se aqui as Teses ou Proposições (III) espinosanas: 1- a substância é, de acordo com sua natureza, anterior às suas afecções; 2substâncias, que contêm, indubitavelmente, atributos diferentes, nada têm de comum entre si, pois uma não pode ser a causa da outra; 3- das coisas, que não têm nada em comum uma com a outra, nenhuma pode ser a causa da outra; 4- mas ou pelos atributos da substância ou pelas afecções desta podem duas ou mais coisas ser distintas entre si; 5- mas há apenas uma, não duas ou mais substâncias; 6- a substância não pode, assim, ser produzida por outra, senão ela não seria, então, substância; 7- por isso, ela é causa de si mesma, isto é, a existência pertence já à natureza da substância ou sua sua essência contém necessariamente a existência; 8- de fato, a substância é incondicionalmente infinita, senão deveria ela ser limitada por outra substância, o que seria uma contradição em si mesma, pois 9- a substância absolutamente infinita é indivisível (cf. Espinosa, Ética, livro I; Spinoza, 1977, pp.5-31)

Há em Espinosa, como mostrado, somente uma única substância, necessária, autônoma e causa sui, e, com isto, está superada toda a contradição (cf. ibidem, proposições 5 e 8), pois o pensamento (o espírito) e a extensão (a matéria) constituem, para ele, apenas atributos (características, qualidades) dessa substância, que é "o ente absolutamente infinito" (cf. ibidem, definição 6), ou algo que inclui necessariamente em si toda a realidade. Tudo o que é, existe necessariamente na substância; assim, não há na filosofia espinosana nenhuma teleologia, mas apenas necessidade na natureza, pois, para ele, todas as teleologias são meramente conceitos ou representações humanas. Essa necessidade da natureza (Naturnotwendigkeit) pode ser expressa em Espinosa da seguinte forma: toda coisa existente na natureza só pode consistir se houver uma causa para a sua existência. Essa causa é também novamente determinada por outra causa e, assim, até o infinito (ad infinitum). Essa causalidade (Ursache), a saber, o universo submetido à relação de causa e efeito, é determinada novamente por outra causa, a causa de si mesma, ou seja, pela substância. Apenas esta é em si e por si 
mesma e, precisamente por isso, a essência não se diferencia, de maneira nenhuma, de sua existência. Disso segue-se que uma tal substância (ou Deus) não existe, precisamente, em nenhum ser particular ou finito (isto é, em nenhuma existência individual ou pessoal), porque ela, como causa sui, como essência infinita, contém necessariamente em si também a sua absoluta existência. A substância é, para Espinosa, a essência única, singular, universal, e, assim, todos os demais seres (ou todas as coisas finitas e determinadas) representam apenas modos (Modifikationen ou maneiras determinadas) da mesma substância, pensados sob diferentes atributos, como as coisas materiais (forma, movimento, repouso etc), representadas pelo atributo extenso, e as coisas espirituais (idéia, vontade, entendimento etc), representadas pelo atributo pensante, os quais não têm, sozinhos, nenhuma realidade para si, porque eles não existem enquanto tais, em si, mas apenas como afecções da substância. O que distingue todas as coisas finitas em sua essência, no entanto, é, em rigor, sua determinidade, a qual Espinosa trata, no entanto, apenas como limitação da realidade. Espinosa concebe, por isso, a substância como um todo, como um indivisível, que é o real das partes. A substância não tem nenhuma parte composta de coisas; ela é, pelo contrário, a absoluta unidade (o absolute prius), sem a qual as coisas finitas não podem existir nem ser pensadas.

Segundo Feuerbach, pertence a Espinosa o grande mérito de haver submetido a oposição das partes e do todo, do corpo e da alma, da natureza e do espírito à unidade da substância, já que toda parte singular da substância pertence à sua natureza. Apesar disto, acentua Feuerbach, e aqui em concordância com Hegel, que Espinosa não tinha reconhecido a substância como espírito e o espírito como substância, ou seja, não tinha determinado a substância como espírito. Por isso, ele não chegou não só ao princípio da unidade como também ao da diferença e não encontrou a verdadeira unidade. A objeção de Feuerbach contra Espinosa consiste precisamente nisto, a saber, que a unidade de Espinosa não foi determinada suficientemente, porque falta a ela a realidade da diferença, da determinidade. A filosofia de Espinosa é, na verdade, uma filosofia da identidade, isto é, da identidade de Deus e natureza, de substância e modos (acidentes), do universal e do singular; assim, carecem ao conceito espinosano de substância a diferença, o princípio da autonomia, da autodeterminação, que se encontra, no entanto, expressamente na filosofia leibnizeana. Além disso, podemos aqui assinalar o seguinte: se a existência real (isto é, a substância), que não inclui nenhuma negation, é em Espinosa verdadeiramente infinita e ilimitada, assim o conceito da infinitude (infinitus) e o da existência é na substância apenas um e o mesmo conceito. Em oposição a isso, a finitude (finitus) tem uma existência finita, portanto, nenhuma existência verdadeira, mas apenas negativa. Por isso, pertence a ela como finitude apenas um 
não-ser, isto é, nenhuma existência real. Uma existência verdadeira têm as coisas, portanto, apenas na indeterminidade, na infinitude, mas, desta maneira, elas não são mais determinadas e diferentes umas das outras, não mais distintas entre si. Na verdade, pertencem às coisas finitas também ser e realidade, mas meramente em forma finita, pois é impossível que pertença à coisa finita o ser no sentido ilimitado. O ser positivo e verdadeiro é para Espinosa indivisível, simples e uno, isto é, ele é mesmo indeterminado e ilimitado, já que a limitação é múltipla ou se deixa dividir. Assim sendo, é lícito afirmar que há em Espinosa, apesar da unidade da substância, um hiatus, ou seja, uma cisão entre duas regiões, a saber, o finito e o infinito, em que da finitude resultam sempre apenas coisas finitas e da infinitude somente a infinitude.

Depois destas considerações, é necessário agora ressaltar algumas categorias específicas, essenciais ao pensamento espinosano. Para isso, podemos contar, por exemplo, com o conceito da unidade (Einheit) da essência e da existência, ou, melhor escrito, da reconciliação (Versöhnung) do espírito e da matéria na idéia da substância mesma. Na sétima tese de sua Ética, Espinosa asssevera que a existência pertence à natureza da substância, pois, se uma substância não pode jamais ser produzida por outro, ela inclui em si, de maneira necessária, a existência. Finita também ela não pode ser, porque ela seria limitada. Assim, fica implícito que a substância existe como infinita. Espinosa supõe que os homens, os quais não estão habituados a reconhecer as coisas de acordo com a sua causa primeira, terão dificuldades para entender a Argumentation de suas teses, porque eles não fazem nenhuma distinção entre os modos (Modifikationen) da substância e a substância mesma e, por isso, não sabem de que maneira as coisas foram produzidas. Em tais casos, devemos, consoante Espinosa, compreender por modos aquilo que se encontra em outro, ou aquilo cujo conceito pressupõe o conceito da coisa, no qual ele é. Os modos, os quais, como as afecções, não podem ser pensados sem a substância, pois constituem a totalidade das as coisas finitas, o composto, o que nasce e perece, por isso eles são contingentes, temporais, efêmeros, mortais. Ao contrário disso, a substância existe em si porque ela só pode ser concebida por si mesma.

Feuerbach diz que Espinosa trata a substância como um conceito, "com o qual seu objeto está dado imediatamente, de modo que a substância é aquilo em que o pensar não é diferente do ser" (Feuerbach, 1969, p.392). A Espinosa não é, no entanto, suficiente o ser no contexto da experiência, isto é, não lhe basta o ser na circunferência dos objetos empiricamente percebíveis, observáveis; pelo contrário, ele quer o ser com o qual o pensar é idêntico. O ser da substância, ou seja, o ser real e substancial diferencia-se, por isto, do ser sensível, que é apenas o ser das modificações finitas, dos compostos. O que confere uma colocação específica, especial, ao conceito 
de substância em Espinosa é que nele a identidade do pensamento (espírito) e da extensão (matéria) está envolvida. Feuerbach compara a substância de Espinosa, metamorforicamente falando, como uma luz:

Tal como a luz se revela a si mesma como luz, assim se manifesta a substância como substância e, precisamente com isto, como existência, como realidade. (...) Assim como o ver é a manifestação imediata da realidade da luz ou a imediata manifestação da luz como luz, a afirmação que é luz e não escuridão, assim também o pensamento da substância é a manifestação imediata de sua realidade, a afirmação da mesma como substância e, com isto, como realidade. (idem, p.395)

Impoõe-se destacar o fato de que disso não se pode nem perguntar, nem duvidar, se corresponde à substância em Espinosa uma existência (ou realidade), pois o despojamento (a privation) de sua existência constituiria não só uma limitação do conceito da substância, como também total negação desta. Para demonstrar a existência da substância, Espinosa forma, segundo Feuerbach,

pura e simplesmente, conceitos imediatos, que não se resultam de outros e não dependem deles, conceitos mesmo simplesmente positivos, de si e por si, isto é, conceitos que se afirmam imediatamente como verdadeiros, porque eles expressam tãosomente o positivo ou o real, porque eles são a afirmation imediata da existência de seus objetos. (idem, p.396)

Ao conceito da substância correspondem, por conseguinte, conceitos imediatos, independentes, infinitos, os quais Espinosa designa como os atributos (indeterminidade, universalidade, ilimitação, autonomia, Abstraktion etc) da substância.

A essência da substância chama-se poder, potentia (Vermögen), porque é de sua essência que tudo dela provenha. A substância infinita (Deus) existe, de acordo com a position de Espinosa, de maneira necessária, pois "não-poder-existir" é, como por si mesmo se esclarece, uma impotência, uma incapacidade, e, ao contrário disso, "poder-existir" é uma potência. O atributo da extensão é, por exemplo, a potência para se produzir formas; do mesmo modo, o atributo do pensamento é a capacidade para se produzir idéias. Diante disso, a substância é a potência, da qual em geral tudo foi produzido. Se, por conseguinte, aquilo que agora existe necessariamente fosse apenas existência finita (ou uma essência limitada), teria esta mais potência e poder do que a substância infinita, o que constituiria uma contradição. A essencialidade absoluta, o ser absolutamente infinito, que inclui, ao mesmo tempo, em si a existência, nomeia Espinosa, como expresso, a substância. A existência e a essência da substância são, pois, em Espinosa idênticas, unas, pois "a substância não deve a sua realidade e perfeição 
a nenhuma causa externa; por conseguinte, a existência deve seguir também de sua essência, e sua existência é nada mais do que sua essência" (idem, p.398). Porque a substância é infinita e absoluta, segue-se disso que pertence a ela também infinitos atributos. Mas verifica-se que Espinosa menciona, na verdade, apenas dois atributos (Attribute), a saber, o atributo extenso (a extensão) e o atributo pensante (o pensamento). O pensamento é, em Espinosa, "um atributo de Deus, ou Deus é uma essência pensante; do mesmo modo é, todavia, a extensão um atributo de Deus, ou Deus é uma essência extensa" (ibidem); quer dizer, Deus est res cogitans, Deus est res extensa. Embora os atributos, como atributos, sejam distintos e separados entre si, eles são, em relação à substância, dependentes, paralelos: um atributo pensante e um extenso da mesma e única substância. Este pensamento espinosano que atribui à substância (Deus) não apenas a qualidade essencial do pensamento, mas também a qualidade essencial da matéria, isto é, da extensão, é ao homem religioso inconcebível, ininteligível, pois, para ele, não pertence ao corpo, como limitação, finitude e imperfeição, a substância absoluta e infinita. O corpo é para o crente (o fiel) algo finito e passivo, conseqüentemente, ele representa uma "determinação indigna" à substância (ou a Deus), que deve ser pensada como indivisível, una e infinita. Isto é evidente, na medida em que se entende por um corpo uma extensão determinada de uma forma limitada. Com isto ele não pode pertencer à substância infinita. O que é, afinal, extensão para Espinosa? É ela a forma de uma essência incorpórea, imaterial, a forma universal de toda matéria? Ou é ela uma determinidade, isto é, divisível, composta? Espinosa interpreta a extensão de maneira dupla: a) por um lado, como modo da representação sensível, para a qual a extensão é divisível e composta (isso vale apenas para os modos da substância); e b) por outro lado, como atributo da substância, para o qual a extensão é indivisível, apenas forma (isso corresponde à essência da substância). Para tornar clara e inteligível esta diferença, poderíamos recorrer, por exemplo, à categoria da quantidade, conforme está ela contida na representação sensível, isto é, finita, divisível, composta etc, e como existe ela no conceito, ou seja, infinita, indivisível etc. O exemplo de Espinosa é a água: como matéria, que encontramos na realidade, nasce e perece a água, mas, como forma, ela é incriada, imperecível e indivisível. Feuerbach critica Espinosa, porque este faz da extensão, da matéria, um atributo divino. A extensio abstrata, separada de todas as determinações, que a extensão tem na intuição sensível (na apreensão direta, na percepção imediata do objeto), é, para Feuerbach, mais cogitatio do que extensio. A água, por exemplo, reduzida a uma determinação da extensio pura, não é mais, para Feuerbach, nenhuma água, mas um objeto ou uma coisa da razão. A Espinosa dirige Feuerbach, criticamente, as seguintes palavras: 
Acredite-me, magnífico Espinosa, apenas a água, que tem uma existência corruptível, tem também uma existência real e necessária! Ou tu não acreditas que a água, que deleita meus olhos e ouvidos, que fortalece meus membros, que mata a minha sede ardente, a água sensível, é uma essência infinitamente rica de atributos e, por conseguinte, de acordo com tua própria filosofia, uma essência divina, como a água não-sensível e sobrenatural, que é uma essência do pensamento privada de todas as suas qualidades individuais? (...) A mim é o entendimento, assim como é para ti, sagrado, mas eu quero que meu entendimento seja com consciência, o que ele é, em verdade: a afirmação, mas não a negação da sensibilidade; eu quero pensar como tu, eu quero queimar meu cérebro não no fogo da sensibilidade; mas eu quero pôr em meu corpo (...), como um não-ens, como um não-ser, o que eu afirmo com todos os meus sentidos e membros como uma essência e, na verdade, como uma essência verdadeira, real. Eu quero me reconhecer como verdadeiro, o que eu sinto como real, mas eu quero sentir também como uma essência real e, por conseguinte, sensível, o que eu reconheço como essência verdadeira. Eu não quero ser um burguês de dois mundos, um mundo intelectual e um mundo sensível, eu quero ser e permanecer lá com minha alma, onde eu sou com meu corpo. (idem, p.449)

Aqui, é interessante, sobretudo, evidenciarmos como a extensão (a matéria) constitui em Espinosa também um atributo da substância. Para entendermos isto, todavia, devemos primeiro tomar em consideração a idéia de que "pertencem" à extensão, na filosofia espinosana, "as determinações da infinitude, da singularidade e da indivisibilidade" (idem, p.400), já que elas, assim como o pensamento, expressam a essência da substância. A extensão, como atributo da substância, constitui para Espinosa precisamente a natureza do corpo, a essência comum de todos os corpos determinados e singulares. Estes não têm em si e para si nenhuma existência, porque eles não podem ser pensados sem a extensão. Enquanto o corpo implica, então, apenas determinidade, divisibilidade, limitação, como algo negativo e finito, a extensão não inclui, ao contrário, em si nenhuma limitação, nenhuma negation ou determinidade. A extensão é realidade indeterminada, ilimitada, cuja essência é apenas forma, um ser puro, uma position pura. Isto esclarece Feuerbach da seguinte maneira: "Um corpo determinado (...) é uma limitação da extensão ilimitada e indeterminada, por isso em si mesmo apenas limitação, privation do ser puro, um ser finito, negativo, um não-ser" (idem, p.401). Desta afirmação, que apresenta o corpo como algo negativo, resulta que a extensão, considerada em sua totalidade e infinitude, não conhece nenhum limite, porque se encontra em seu conceito nada mais do que ela mesma, já que ela consiste apenas em si e de si mesma. Espinosa concebe a extensão apenas por ela mesma, pois seu conceito não depende do conceito de outra coisa, razão pela qual ela é indissolúvel, indivisível.

Precisamente como o pensamento, a extensão é, para Espinosa, apenas um dos ou um entre os infinitos atributos da substância. Ambos expressam, cada qual sob seu modo determinado, a essência da substância. Segundo 
Feuerbach, aqui comete Espinosa, na verdade, uma contradição, a saber: a extensão é um atributo da substância, contanto que ela seja, em seu modo, indeterminada, ilimitada. Isto é, ela não expressa de maneira concreta o ser, por isso o real consiste nela meramente como uma realidade abstrata e indiferente. A extensão como determinidade, como e o que ela é, significa para Espinosa apenas não-ser. O mesmo vale para o pensamento. De ambos os atributos permanece, por conseguinte, nada mais do que a determinidade abstrata, quantitativa, ou seja, o número, que elas são apenas dois atributos infinitos e indeterminados da substância. É indubitável que o pensamento e a extensão em Espinosa são bem diferentes um do outro, embora

\begin{abstract}
eles expressem, sim, uma e a mesma essência, uma e a mesma coisa, a saber, a substância, que é frente a isto indiferente, se ela foi concebida como extensão ou como pensamento, e nisso são eles um com a substância. Mas já que eles expressam e representam apenas de uma maneira determinada a substância, são eles para ela um não-ser, é sua diferença em relação a eles, por conseguinte, irreal. (...) Ambos os atributos se perdem e desaparecem sem apoio, sem consistência, (...) como dois atributos na pluralidade infinita dos outros atributos não conhecidos, os quais, na verdade, cada qual numa certa maneira, expressam a substância, mas, já que esta certa maneira como um modo determinado é uma irrealidade, eles não se diferenciam um dos outros como eles são na pluralidade. (idem, p.407)
\end{abstract}

Assim, evidencia-se aqui, na filosofia espinosana, uma falha que provém da absoluta indiferença que a substância tem para a determinidade, e seus atributos são, por isso, nela e em si indiferentes e infinitos. A substância como existência (como realidade ou como unidade) é deficiente, porque ela é existência pura, incondicionada e indeterminada, e, com isso, falta a ela o princípio da diferença, da determinidade. Neste sentido, podemos afirmar que a substância de Espinosa, apesar de sua relevância, não apresenta ainda uma solução adequada no que diz respeito à problemática da relação entre espírito e matéria (natureza), porque ela, do mesmo modo como seus atributos, é totalidade sem realidade, ou melhor, realidade abstrata, vazia, sem conteúdo e não concreta. Podemos ainda verificar, já no começo da Ética de Espinosa, que o conceito de ambos os atributos e sua relação para a substância remetem a outro problema. O pensamento e a extensão apresentam-se essencialmente diferentes entre si, pois o pensamento não pressupõe a extensão e esta não aquele, já que cada qual é para si mesmo um atributo absoluto: os atributos são definidos como autônomos e independentes um dos outros. Se o pensamento e a extensão, porém, não são idênticos, expressam, todavia, simultaneamente, a mesma substância, como pode, então, a substância ser uma unidade? Já que os atributos são distintos e, ao mesmo tempo, constituem a essência da substância, então a substância possui, considerada sob este ângulo, uma essência dupla, em si 
diferente. Os dois atributos produzem, evidentemente, na substância uma separação que não está em sintonia com o conceito da unidade da substância espinosana.

É ainda importante analisar, neste lugar, o que Espinosa entende por natura naturans (natureza "naturante") e natura naturata (natureza "naturada"). Por natura naturans (natureza original), entende ele aquilo o que existe em si ou é concebido por si mesmo. Espinosa designa esta natureza como a natureza ativa, livre, causal ou autocriadora, isto é, como a natureza simples e indivisível, que significa, precisamente, a substância infinita (Deus). Por natura naturata (natureza originada, nascida, realizada), ele concebe, ao contrário, como natureza passiva, criada, como tudo o que segue necessariamente da natureza de Deus (da substância) e de seus atributos, isto é, todos os modos dos atributos de Deus, na medida em que estes foram considerados como coisas finitas, como qualidades determinadas, como compostos. A frase Deus sive substancia sive natura (Deus é tanto substância como natureza), isto é, natura naturans e natura naturata, ou seja, substância e modos (acidentes) simultaneamente, explicita Espinosa da seguinte maneira: Deus é a natureza (Natur) infinita, absoluta (naturans), e tudo o que é, isso foi tornado (naturata) por ele. Isto é, os modos (Modi), embora pertençam à natureza realizada, resultam da natureza divina. Se Deus é absolutamente infinito e tudo nele sumamente perfeito, pois tudo segue necessariamente de sua essência perfeita, são o mal e a imperfeição nada objetivo, real, por conseguinte a natureza das coisas é sempre perfeita e boa. Se tudo, no entanto, está determinado pela natureza perfeita de Deus, e se Deus é igual à natureza, de onde vem, pois, tanta imperfeição da natureza, como, por exemplo, a corrupção, a degenerescência das coisas, a fetidez, a fealdade repugnante, a confusão de todas as ordens, como os males, as dores e os padecimentos no mundo? Para Espinosa, as coisas, segundo sua natureza e sua essência, não se apresentam, na verdade, nem perfeitas nem imperfeitas, porque perfeição (o bom ou o bem) e imperfeição (o ruim ou o mal) dependem tão-somente dos juízos dos homens. As falhas ou imperfeições da natureza pertencem, na filosofia espinosana, assim, não à natureza mesma, mas, pelo contrário, à representation e valorização humanas da natureza: sobre o fundamento de um juízo ou modelo, que os homens formam e preservam, em suas representações, como arquétipo das coisas, nomeiam eles as coisas da natureza perfeitas ou imperfeitas. Assim sendo, perfeição (Vollkommenheit) e imperfeição (Unvollkommenheit) são nada mais do que certos modos, maneiras determinadas de se pensar, por assim dizer, predicados, os quais os homens agregam à coisa. Já que falhas, limites, imperfeições etc. são nada reais, nada positivos, ou seja, não têm nenhuma autonomia, nenhuma realidade objetiva e substancial na natureza, pode-se falar em Espinosa de uma Ética ou de uma Doutrina Moral apenas sob reservas. 
A limitação, a imperfeição, o erro, o mal, assim como o bem, não têm nele igualmente nenhuma essência em si, pois eles são apenas modos finitos de representações, conceitos e valores relativos, os quais os homens formam a partir da comparação de uma coisa com outra.

Concluindo, chamamos a atenção para a noção de que aquilo designado por Espinosa metafisicamente como substância ou teologicamente como Deus significa nada mais do que a natureza num sentido metafísico. Espinosa identifica a substância apenas com a natura naturans (com a natureza abstrata, indeterminada, Deus), mas não com a natura naturata (com a natureza concreta, objetiva, sensível, qualitativa). Em Espinosa,

Deus e natureza são sinônimos, equivalentes, pois o poder, pelo qual as coisas singulares e, por conseguinte, o homem obtêm o seu ser, é mesmo o poder de Deus ou da natureza. O poder do homem é, por conseguinte, uma parte do poder infinito de Deus ou da natureza. (idem, p.445)

Ou, ainda mais claro: "só a força e o poder da natureza é a força e o poder de Deus mesmo, pois a potência do efeito, o poder de uma coisa é sua essência mesmo, então a essência da natureza é a essência de Deus mesmo" (idem, pp.447-8). A natureza é o princípio, a essência da filosofia espinosana. A qual natureza, entretanto, se refere Espinosa? A natureza de Espinosa não é nenhum objeto da sensibilidade, nenhum exterior, externo, nenhum outro visível, manifesto, mas uma essência abstrata, não sensível, metafísica, que não tem nenhuma realidade fora da substância (de Deus). A natureza, deduzida por ele teológica ou metafisicamente como objeto de Deus, não é para se entender como natureza em sentido qualitativo, objetivo e sensível, pois ela está separada da divisibilidade, da multiplicidade e de todas as determinações, que ela contém em sua realidade sensível, objetiva. Ante Espinosa, para quem a natureza é idêntica com a substância isto é, a expressão das qualidades internas de Deus, como singularidade, perfeição, eternidade, universalidade etc, pois Deus como substância é para ele a natureza infinita, pura, não a natureza finita, "suja" ou "manchada", Feuerbach a designa, em verdade, como fundamento e objeto sensível, qualitativo e material da vida humana. Não há em Feuerbach um dualismo entre natureza criadora e natureza criada, entre natureza indeterminada e determinada, pois há para ele, na realidade, apenas uma natureza, à qual o homem deve a sua existência. A position de Espinosa, segundo a qual a natureza é indivisível, simples, sem diferença, expressa tão-somente uma concepção abstrata de natureza. Sob este aspecto, poder-se-ia suscitar perante Espinosa as seguintes questões: como se pode reduzir a natureza, ante a totalidade de seus elementos, na forma de uma simples substância? Se a natureza divina não se apresenta nas plantas, nem nos animais, nem 
nos homens, nem no universo das coisas finitas, que sentido se ergue, então, para se falar ainda de natureza? Como pode uma natureza finita, qualitativa, objetiva, na qual valem, por exemplo, as leis pretensas da natureza, ser ainda pensada na e com a natureza absolutamente infinita? Como é possível uma natureza atemporal, não externa, simples e indivisível determinar o composto, a pluralidade, isto é, a natureza realizada? A tais questões Espinosa não dá nenhum resposta. Trata-se, portanto, de reivindicar, e é isto que Feuerbach quer, não mais uma identifikation da substância com a natureza, uma imanência de Deus no mundo, isto é, não mais um "Deus sive natura" (um Deus que é tal como a natureza), como que designações da substância única, infinita (Deus e natureza são um = panteísmo), mas a separação entre Deus e natureza, ou seja, a desição "aut Deus, aut natura" (ou Deus ou a natureza). Onde Deus foi identificado, em sentido abstrato, com a natureza ou, ao contrário, a natureza objetiva confundida com Deus, lá não estão nem Deus nem a natureza. Desta maneira, chegamos aqui à conclusão que o segredo da filosofia de Espinosa consiste numa negação da Teologia sob o ângulo da Teologia. Assim, a filosofia de Espinosa é mesmo Teologia, ou, melhor expressando, uma negation teológica da Teologia.

CHAGAS, E. F. Feuerbach and Spinoza: god and nature, dualism ou unity? Trans/ Form/Ação, (São Paulo), v.29(2), 2006, p.79-93.

- ABSTRACT: This article on the one hand offers evidence of Spinoza's philosophical merit due to the fact that he propounded the opposition of substance of parts and whole, body and soul, matter and spirit, to unity of substance, since every single part of substance belongs to nature. And on the other hand it presents Feuerbach's critique of Spinoza since Spinoza's philosophy is in fact an identity philosophy which does not recognize, as Hegel also points out, the substance of spirit and the spirit as substance, and does not clearly determinate the unity of matter and spirit because it lacks the truly aspect of difference, determinacy. While Spinoza identifies God with nature (Deus sive natura) and by means of divine nature (substance) overcomes Descartes' contradiction between matter (res extensa) and spirit (res cogitans), Feuerbach wants, in opposition to pantheism, determine the difference between nature and God (aut Deus aut natura).

- KEYWORDS: God and nature in Spinoza; Spinoza critic; Feuerbach

\section{Referências bibliográficas}

CHAGAS, Eduardo Ferreira. "Projeto de uma Nova Filosofia como Afirmação do Homem em Ludwig Feuerbach". In: Teoria \& Praxis - Revista de Ciências Humans e Política, n.4, Goiânia-GO: 1992, p.31-36. 
CHAGAS, Eduardo Ferreira. "A Autonomia da Natureza em Ludwig Feuerbach". In: VASCONCELOS, J. G. (org.). Filosofia, educação e realidade. Fortaleza: Editora UFC, 2003, p.69-79.

"Religião: O Homem como Imagem de Deus ou Deus como Imagem do Homem?". In: OLINDA, E. M. B., Formação humana: liberdade e historicidade. Fortaleza: Editora UFC, 2004, p.86-105.

"Kritik des Anfangs der Philosophie Hegels in der Logik und Phänomenologie des geistes". In: Festschrift zu Hans-Georg Flickinger. Göttingen, Civilier Verlag Göttingen: 2004, p.63-76.

CORNEHL, Peter. "Feuerbach und die Naturphilosophie. Zur Genese der Anthropologie und Religionskritik des jungen Feuerbach". In: Neue Zeitschrift für systematische Theologie und Religionsphilosophie, t. 11, Berlin: 1969, p.37-93.

DESCARTES, R. Meditations. Bridoux, A. (org.), Paris: 1953.

FEUERBACH, L. Geschichte der neuern Philosophie von Bacon und Verulam bis Benedikt Spinoza (1833). In: W. Schuffenhauer (org.), GW 2, Berlin: 1969.

MÜNZ, Theodor. "Spinoza, Feuerbach und die Würde der Natur". In: Brau, H. -J. et alli (org), Ludwig Feuerbach und die Philosophie der Zukunft. Berlim: 1989, p.55-67.

SCHUFFENHAUER, Werner. "Aut Deus - Aut Natu. Zu Ludwig Feurbachs Spinoza und Leibniz-Bild". In: Lo spinozismo ieri e oggi, Archivio di Filosofia. Padova: 1978, n.1, p.267-291.

SPINOZA, B. Ethik. Gibhardt,V. C. (org.). Stuttgart: 1977.

SOUZA, Draiton Gonzaga. "Das Verhältnis des Menschen zur Natur". In: Ethik Ludwig Feuerbachs. Göttingen, 1998, p.55-93. 